\title{
Changing trends in cesarean section: from 1950 to 2020
}

\author{
Babulal S. Patel*, Noopur Kedia, Sushma R. Shah, Saumya P. Agrawal, Vismay B. Patel, \\ Adwait B. Patel
}

Department of Obstetrics and Gynecology, Smt NHL Municipal Medical College, Sheth V S General and Sheth C M Hospital, Ellisbridge, Ahmedabad, Gujarat, India

Received: 05 February 2020

Accepted: 29 February 2020

\section{*Correspondence:}

Dr. Babulal S. Patel,

E-mail: babu_pate1007@hotmail.com

Copyright: (c) the author(s), publisher and licensee Medip Academy. This is an open-access article distributed under the terms of the Creative Commons Attribution Non-Commercial License, which permits unrestricted non-commercial use, distribution, and reproduction in any medium, provided the original work is properly cited.

\begin{abstract}
Caesarean section (C.S) is a part of the standard care in modern obstetrics. The indications for a caesarean section as an alternative to vaginal delivery have evolved over the centuries. Its practicality, disponibility, and apparent safety have placed caesarean section, a first-line procedure in many clinical scenarios. The awareness of perinatal mortality and morbidity associated with safety of caesarean, expert anaesthesia, potent antibiotics, blood transfusion facilities and better neonatal care have increased incidence of caesarean section very fast. Thus, there is fast, steady and definite rise in incidence of caesarean section everywhere. But the question is 'Is a rising caesarean section rate is inevitable?'. Studies carried out to understand CS deliveries has adopted different framework. The issue treats elements of ethics in the medical profession, gender issues, choices of women, the quality of institutional services, etc. The findings of retrospective studies have suggested that the caesarean section rate could be reduced in certain categories. In this study, we discuss the various ways in which it can be achieved.
\end{abstract}

Keywords: Caesarean section, Changing trends, Indications, Influences, Judicious approach, Vaginal delivery

\section{INTRODUCTION}

"The art of surgery has not replaced the older art of obstetrics; it has only softened it, for it is of gentler kind." Marshall, 1955.

Caesarean section (C.S) is a part of the standard care in modern obstetrics. During the last 70 years, institutionalisation of delivery pretended to make child birth a safer event. Today caesarean section is an active part of obstetrical practice with aims to improve clinical performance and perinatal indicators. The indications for a caesarean section as an alternative to vaginal delivery have evolved over the centuries. From remote anecdotal references in history of medicines, caesarean section has evolved to be part of the standard of obstetrical care today. ${ }^{1}$ Its practicality, disponibility, and apparent safety have placed caesarean section a first-line procedure in many clinical scenarios.
Significant variations are apparent between first and third world economies, health models, the standard of obstetrical care, obstetrical risk factors, reimbursement and cultural influences. This article aims to study the trends and the causes of such trends seen in caesarean section over the past 50 years. ${ }^{1}$

\section{REVIEW OF LITERATURE}

\section{Historical background}

Caesarean section is almost certainly one of the operations of great antiquity and its origin is lost in mythology. The term "caesarean" most probably comes from the Roman term "caesomatris" which meant cutting a fetus out of the maternal womb. The law Lex Regia (Numapompilius) or Lex Cesarea ordered the fetal extraction out of the maternal uterus in case of maternal 
death for an individual burial. Jacques Guillemeau (1598) was the first author to use the term "section" to refer to the caesarean intervention as a birth choice.

The main indication for practicing a caesarean section has not always been maternal and fetal health. There are reports of religious indications in ancient Egypt (3000 BC) and in India (1500 BC). The Jewish Mishnah (140 BC) established that for twins, birth by caesarean section for both products and privileges to claim primogeniture. The Council of Colonia (1280) made it mandatory to perform cesarean section when the mother died. In the Republic of Venice (1608) penalties were imposed on physicians who failed to make an attempt to save a soul in cases of maternal death. In the United States (17691833 ) it was mandatory for the Franciscan missionaries to have the knowledge and dexterity of how to practice a section. ${ }^{1-3}$

\section{Evolution of caesarean section}

Francois Roussette (1530-1603) was the first physician to refer caesarean section as a procedure for living women (Paris 1581: Traitté nouveau de l'hysterotomotokie, ouenfantement). Roussette referred for historical purposes the story of Jacob Nufer (1500), a swine castrator from Switzerland, apparently was the first documented man to perform a successful caesarean section on Elizabeth Alice Pachin, his wife who had a prolonged and dystocic labor during her first pregnancy.

He performed an abdominal and uterine incision with a blade, extracted the fetus and sutured the abdominal wall. The patient survived and subsequently had vaginal deliveries, including twins. The new born lived until the age of 77 years. $^{3}$

However, caesarean sections as a surgical option in cases of dystocia historically were delayed in the practice of obstetrics due mainly to three elements:

1. It was a late procedure in a patient already complicated,

2. Infection and,

3. Hemorrhage.

Trautmann of Wittenberg (Nuremberg, Germany-1610) practiced the first medically documented cesarean section in a living woman. The patient died 25 days later due to sepsis. By 1865 , the maternal mortality rate of CS practiced for maternal indications was estimated to be around $85 \% .^{1-3}$

In the historical evolution of CS practiced for maternal indications, some important mile-stones for the reduction of complications and increase in survival are; ${ }^{4,5}$

- The description of a transverse incision technique by Ferdinand Adolf Lehrer (1881).
- Joseph Lister (UK-1860) description of the use of carbolic acid as an antiseptic.

- $\quad$ use of silver and silk sutures for peritoneal closure by Max Sanger (1882).

- Abdominal incision by Hermann Johannes Pfannenstiel (1912).

- Munro Kerr (UK-1929) described the transverse incision on the uterine segment.

Later in medicine, the implementation and improvement of surgical techniques, anesthesia, blood transfusion, and antibiotics impacted positively in the performance and prognosis of $\mathrm{CS}$ as an alternative option to vaginal delivery. However, application of Anesthesia in obstetrics did not happen so fast due to the belief according to the Biblical mandate that women should suffer" pain" while birth. This argument lost value when Queen Victoria of England, head of the English church received chloroform during the birth of their children Leopoldo (1853) and Beatriz (1857). ${ }^{3}$ From 1880 to 1925 , several techniques of extra-peritoneal CS and vaginal caesarean were described in order to decrease infection. The need of these techniques for caesarean disappeared after 1928, with the discovery of penicillin, which became available in 1940.

\section{Changing rates of caesarean section over the world}

In the days of modern obstetrics, focus of obstetrics thinking has changed increasingly towards the perinatal survival and prevention of birth trauma to the baby. The awareness of perinatal mortality and morbidity associated with safety of caesarean, expert anesthesia, potent antibiotics, blood transfusion facilities and better neonatal care have increased incidence of caesarean section very fast.

The CS rate in the United States has changed dramatically during the last 50 years. 1970:5\%, 1990:23.5\% and 2016:31.9\% (low-risk patients:26.9\%). ${ }^{6,7}$

The rising caesarean section rate in the United Kingdom continues to generate many debates in Scotland. The caesarean rate rose from $8.5 \%$ in 1975 to $16 \%$ in 1994 . In 1985, the WHO stated that the CS should not exceed $15 \%$ in any population group. ${ }^{7}$ In last decades, an invariable upward trend has been evident mainly in low- and middle-income countries, China $(64.1 \%)$, Columbia (46.4\%), Dominican Republic (56.4\%), Egypt (51.8\%), Iran (47.9\%) and Brazil (55.6\%). $80 \%$ for second deliveries when the first was by caesarean, are some examples. ${ }^{8,9}$

In some countries the rate varies widely from $45-50 \%$ (Mexico and Turkey) to $15-17 \%$ (Netherland, Sweden, and Norway). In other European countries like France the CS rate has been relatively stable: $20.4 \%$ in $2003,21.1 \%$ in 2010 , and $20.4 \%$ in $2016 .^{8,10,11}$ A study conducted by Stavrou et al in New south wales, Australia showed caesarean rate of 29.5 per 100 births in $2008 .^{12}$ 
The unpublished data of one of the teaching institute of Ahmedabad explored caesarean rate of $1.4 \%$ in 1955 , $2.68 \%$ in $1960,3.2 \%$ in $1965,4 \%$ in $1970,6.5 \%$ in 1975 and $11.2 \%$ in 1985 . The CS rate of our institute of the year 1999 is $20.22 \%, 2000$ is $22.14 \%$ and $2019-38.64 \%$

At all India level, the rate has increased from $2.9 \%$ of the child birth in 1992-93 to $7 \%$ in 1988-99 and further to $10.2 \%$ in $2005-06$, according to NFHS data sets. ${ }^{13}$

A study by the Indian council of medical research (ICMR) in 33 tertiary care institutions noted the average caesarean section rate increased from $21.8 \%$ in 1993-94 to $25.4 \%$ in $1988-99$ (Kambo et al).

Thus, there is fast, study and definite rise in incidence of caesarean everywhere. But the question is 'Is a rising caesarean section rate is inevitable?'.

\section{DISCUSSION}

\section{Causes for such a favoring trend for caesarean section}

Analysis of different studies provides interesting information. Most sections $(50 \%)$ are carried out as emergencies during labor, $35 \%$ as elective operations and $15 \%$ are undertaken as emergencies before labor. About half $(50 \%)$ of all singleton caesarean sections are in primiparous women, and among primiparas, emergencies during labour was responsible for about $35 \%$ of caesarean sections.

Four indicators are accounted for $80-85 \%$ of total caesarean sections.

1. Elective operations for breech presentation,

2. Emergency section labor because of suspected growth retardation,

3. Emergency section during labor because of failure to progress and /or fetal distress,

4. Repeat caesarean section.

Interestingly, maternal requests of $8 \%$ in primi cases and $20 \%$ in previous caesarean cases for elective cesarean section have been recorded.

Studies carried out to understand CS deliveries has adopted different framework. The issue treats elements of ethics in the medical profession, gender issues, choices of women, the quality of institutional services, etc.

Modern times have imposed as fundamental principle the fact that "time is money" for which we always live in a hurry, there is no time for communication or patient medical relationship, moral relationship and pragmatism of behaviour predominates. Thus, although birth is profound and powerful human experience and for women generates feelings of empowerment, success and personal achievements, the excessive increase in CS rate is a consequence of medicalization of birth as a change in attitude of the patient and doctor with in the new social model that undoubtedly impacts professional practice. This increased operative intervention poses greater risk of placenta previa in future pregnancies, prolonged hospital stays and increased incidence of respiratory distress syndrome in new-born. Anesthetic complications, infections, lower breast-feeding rates are some other important early complications. In long term prospective, women with previous caesarean are at risk of chronic pain, infertility, bowel obstruction and uterine rupture, additionally babies delivered by caesarean are more likely to have allergies, obesity and other metabolic diseases. Caesarean section has eight-fold higher mortality than vaginal delivery in addition to 8-12 times higher morbidity.

\section{What can we do about it?}

The findings of retrospective studies have suggested that the caesarean section rate could be reduced in certain categories. Reducing the section in primiparas is of utmost importance if the overall section rate is to fall without an increase in fetal morbidity. Attempting external cephalic version at term in women with a breech presentation and no other complications, careful assessment of primigravid women in labor, ensuring that the labor is effective and confirmed diagnosis of fetal distress are important to reduce the unindicated caesarean section. There is also scope to increase the vaginal delivery rate after one previous caesarean section (20\%). Thus, if a substantial portion of previous caesarean patient can deliver vaginally, experience indicates that $60 \%$ or more can the number of caesareans, medical risks and costs be reduced. Collected studies in USA for the last 40 years show an overall $79.6 \%$ VBAC. Thus, it appears that almost four out of five gravidas selected for trial of labor (who represent approximately two third of all patients who have undergone a previous caesarean birth) can deliver vaginally.

The increase in CS rate is also due to increase in number of IVF pregnancies, altered family structures, demanding patients, increase in number of institutional deliveries, referral from peripheral rural hospitals to tertiary care centers.

In 2001, Robson proposed to adopt a standard classification system so that CS rates would no longer be thought of as being too high or too low, but rather whether they are appropriate or not, in the context of all information about clinical variables, including maternal satisfaction. The 10-group classification system (TGCS or Robson classification) is a method that provides essential information regarding common factors for a determined obstetric population where perinatal events and outcome can be established, measured, compared and audited. The classification, however, only takes part of the variables of an obstetric population into account. Important information like maternal age or body mass index (BMI), are not part the classification. ${ }^{14,15}$ 
Although the 1985 recommendation on the CS continues to be referred indicator in obstetric literature, recent evidence based on demographic across the 194 WHO member countries suggest that the optimal global CS rate may be around $20 \%$.

Other nonmedical factors have also been reported: supply-side demand induction, decision issues related to professional convenience and optimization of time and predilection for CS in private versus public hospitals.

In $21^{\text {st }}$ century, professional autonomy is articulated by four factors such as:

1. Self-assessment and self-regulation of medical practice,

2. Responsible use of technology, and

3. Financial factors,

4. Fear of medical litigations.

Trial of labor in selected patients with low transverse caesarean scar is safe and desirable option. Uterine scar rupture during trial of labor occurs rarely, but may be devastating. The physician and patient should select the mode of delivery after thorough consideration and discussion, including a specific management plan. Careful clinical judgement is warranted when counselling for vaginal birth after caesarean, regardless of the type of scar and should take into account the risks and possible sequel of uterine rupture. The policy of "Once a caesarean section, always a caesarean section" should be applied correctly only to its intended group of patients. As the advisability of insisting on a trial of labor for all parturient who have no contraindications becomes a signal part of fabric of obstetric practice, we shall witness the demise of routine repeat abdominal delivery.

\section{CONCLUSION}

The indications for the caesarean section have changed throughout history. They have been shaped by religious, cultural, economic, professional, and technological reasons that have impacted medicine. CS originated as a precept for saving the soul, if not the life of the fetus. From the nineteenth century it changed to save the obstetric patient. Finally, since the end of twentieth century, Western obstetric medicine has focused on the maternal and fetal benefits of the procedure.In the last 30 years, the fetal indications of the procedure have triggered its frequency with a definite impact on the model of modern obstetric practice.

The caesarean section rate varies in different institutions tertiary care centres cannot be expected to have a similar rate as primary and secondary one due to high number of complicated cases refused to them. Though effort should be made to keep CS rate at a low level as suggested by WHO and practices like trial of labour after previous CS should be enthusiastically encouraged, every case should be individualised. Cost effectiveness in low resource setting is an important issue. Though performing caesarean section for non-indicated cases is unethical, denying it for an indicated case just to adhere to keep low rate jeopardizes maternal and fetal health. Hence no definitive guidelines can be followed and a very judicious approach is needed for decision making of CS. Our goal as health providers is to assure that CS is practiced on patients and neonates that will benefit from it.

\section{Funding: No funding sources Conflict of interest: None declared \\ Ethical approval: Not required}

\section{REFERENCES}

1. Trends in Cesarean Section by Andres Sarmiento, Universidad de los Andes, Bogota, Columbia, 2018. Available at: https://dx.doi.org/10.5772/ intechopen.77309. Accessed on $4^{\text {th }}$ January 2020.

2. Caesarean section - A Brief History, 1993. FactsheetNational Library of Medicine. Available at: https://www.nlm.nih.gov. Accessed on $5^{\text {th }}$ January 2020.

3. Boley JP. The history of caesarean section. CMAJ. 1991;145(4):319-2.

4. Pfannenstiel HJ. The advantages of the suprasymphysar fascia cross-section for gynacological coliotomies also contribute to the indication of the surgical routes. In: Collection of Clinical Lectures. 1900;268(97):1735-56.

5. Kerr JMM. The technic of cesarean section, with special reference to the lower uterine segment incision. Am J Obstet Gynecol. 1926;12(5):729-34.

6. Recent trends in cesarean delivery in the United States. Factsheet: NCHS Data Brief, September 2017. Available at: https://www.cdc.gov/nchs/products/databriefs/db287. htm. Accessed on $2^{\text {nd }}$ December 2019.

7. Chalmers. Appropriate technology for birth. Lancet. 1985;2(8452):436-7.

8. Betran AP. The increasing trend in cesarean section rates: Global, regional and national estimates: 19902014 Plos One. 2016;11(2):e0148343.

9. Beogo I. Determinants and materno-fetal outcomes related to cesarean section delivery in private and public hospitals in low-and middle-income countries: A systematic review and meta-analysis protocol. BMC Syst Rev. 2017;6(1):5.

10. WHO Statement on Caesarean Section Rates. Factsheet: World Health Organization 2015. Available at: http://www.who.int/reproductivehealth /topics/maternal-perinatal/cs-statement/en/. Accessed on $15^{\text {th }}$ September 2019.

11. Blondel B. Trends in perinatal health in metropolitan France from 1995 to 2016: Results from the French National Perinatal Surveys. J Gynecol Obstet Human Reprod. 2017;46(10):701-13.

12. Kamal P, Kaur HP, Nagpal M. Is current rising trend of CS justified? Inter J Reprod Contracept Obstet Gynecol. 2017;6(3):872-6. 
13. Ghosh S. Increasing trend in caesarean section delivery in India: role of medicalisation of maternal health. Bangalore: Institute for Social and Economic Change; 2010. Available at: Handle: RePEc:sch:wpaper:236. Accessed on $2^{\text {nd }}$ January 2020.

14. Robson M. Can we reduce the caesarean section rate? Best Pract Res Clin Obstet Gynecol. 2001;15(1):179-94.
15. Robson SJ. Thirty years of the WHO target caesarean section rate: time to move on. Med J Aus. 2017;206(4):181-5.

Cite this article as: Patel BS, Kedia N, Shah SR, Agrawal SP, Patel VB, Patel AB. Changing trends in cesarean section: from 1950 to 2020. Int J Reprod Contracept Obstet Gynecol 2020;9:2222-6. 